\title{
El Area del Idioma "Kauke" en el Perú
}

JOSE MATOS MAR

Trabajo Presentado al ler. Congreso

Internacional de Peruanistas

\section{GENERALIDADES}

Una de las orientaciones que actualmente seguimos en la Einología Peruana es la de conocer las diversas áreas culturales que exister eri nuestro territorio y aún más dentro de lo que fué la antigua área peruana, o sea el Area Andiria. La ubicación de las mismas nos pelmilirá encauzar en mejor forma läs investigaciones que llevamos a cabo y establecer una serie de mapas y esquemas clasificatorics cil. terigan como única misión la de servir de ayuda en la tarea empeñada. Mapas de distribución deddiferentes alementos culturales, tales como el de la takllag instrumentolde labranza, del cuitivo en andenerías, del uso de la quena, de las zonas de supervivencia del antiquo sirvinacuy, de la ganadería de auquénidos, de la utilización del ichu en diferentes usos, de actividades tales corno la pesca, cazd, recolección, ganadería, minería, de la difusión de la marinera, tel wayno, de las cofradías religiosas, etc., eic. Estos mapas de supervi vencias de elementos culturales autóctonos, alienígenas y de lo que ahora es netamente peruano, permitirán un mejor conocimiento de lo que es el Perú actualmente.

Junto con estos mapas tratamos de elaberar esquemas clasificatorios de esos mismos elementos. Esto que a simple vista pudiera parecer fácil, constituye un serio problema de discernimiento por la carencia de estudios en épocas pasadas, necesitamos revisar en especial y cuidadosamente las crónicas peruanas-escritas en los siçios XVI y XVII las que en los últimos años han considerablemente aumentado gracias a la acuciosidad de los especialistas en la materialos documentos en archivos y también estudios posteriores, todo lo 
cual servirá para conocer los elementos aborígenes que corresponden a la Cultura Antigua del Perú, de otra parte las Instituciones, el ambiente, en general la cultura española de los siglos XV, XVI y XVII, a fin de conocer lo que vino, por la vía de España, de la cultura occidental, saber lo que de la misma cultura occidental llegó posteriormente por otras vías como Francia, Inglaterra, etc, y aún más la influencia que la cultura árabe tuvo sobre la de España en más de siete siglos də dominación que acabaron en 1492, muchos de cuyos elementos vinieron traídos por los mismos españoles que los asimilaron. Con esquemas y cuadros clasificatorios podremos poco a poco ir separando estos elementos que integran la cultura peruana. Podremos conocer en este proceso cultural de ajustes y desajustes cuáles ele. mentos culturales superviven, cuáles han sido rechazados, cuáles $\mathrm{c}$ similados, cuáles transplantados, etc. y lo más interesante cuáles son los nuevos elementos creados por los peruanos que difieren de ambos aportes.

Para llegar a establecer estos cuadros culturales necesitamc: precisar las diferentes áreas culturales que existen en el Perú, zonc; geográficas de homogeneidad cultural, donde las formas de vida guardan similitud y que difieren de las de otras zonas. Estas diferencias guarturales en el Perú actual no son marcadamente opuestas, constituye' únicamente matices y peculiaridades lccales de un fondo cultural c:mún; diferenciaciones cultarales quel las podemos notar a diario en la misma carital y manifestada en diversas formas; es diferente un habibitante de la selva que esporádicamente la visita, de un "criollo", de un "serrano", o un blanco; y si nos adentramos en el conocimiento de las Comunidaes peruanas veremos también diferencias marcadas. No es lo mismo Satipo que Chincha, Eten o Monsefú que Capachic:I - Chucuito, Lima que Madre de Dios, ni Virú que Sicaya, etc., etc. Pero, así como hay estas divergencias, también notamos cierta homogeneidad entre grupos ubicados alrededor de un valle, bien sea costeño, serrano o selvático. Los pueblos alrededor del Callejón de Huaylas montienen uniformidad cultural, así como los del valle del Mantaro, del Urubamba, los de la meseta del Collao, valles de seiva como el Huallaga, Marañón y Ucayali, diferentes grupos en la misma selva agrupados alrededor de un río, varios valles costeños como Chicama, Moche, Virú, Chao y Santa en el norte y en el sur Criincha, Pisco, Ica y Nazca, etc. Así mismo hay zonas de gran interacción principalmente entre valles costeños y serranos que marcan zonas de influencia cultural. 
Aparecen bastante marcadas zonas determinadas por situaciones geográficas, por formas similares de trabajo en la explotación de la tierra y algunas de ellas de gran profundidad histórica, con continuidad desde la época pre-incaica hasta la fecha.

La finalidad al ordenar y distribuir en mapas y esquemas los resultados de las investigaciones etnológicas es únicamente el de ordenamiento metodológico. Ellos servirán para sugerir zonas de futuras investigaciones, elaborar planes específicos, tratar de llenar vacíos; ofrecer en principio bosquejos de lo que es la realidad cultural indudablemente que esto en los comienzos tendrá imperfecciones, pero con el avance de los trabajos de campo llegaremos a obtener un cabal conocimiento de dicha realidad.

Esta tarea que nos hemos trazado ya en tiempos atrás otros países la han iniciado. Antes de precisar las características que hacen de la Comunidad de Tupe una zona cultural dentro del Perú, es necesario tene: una mejor ddea de lo que entendemos por área cultural y su posible rroyección al estudio de la realidad peruana.

Los antropólogos en diversas partes del mundo han iniciado desde hace unos 30 años, la clasificación de los diversos continentes en áreas culturales. América, desde 1917, ha sido clasificada con fines puramente metodológicos en diversas áreas de cultura. En 1942 se establecieron las áreas africanas; en 1926 Linton, hizo estudios acerca de las áreas de Madagascaj.OAlfred L. KroeberraGlark Wissler, Johr: Cooper, Melville Herskovits, Wendell Bennett y varics ctros en el "Handbook of South American Indians", entre fos principales, se har ccupado extensamente de este tema para América.

La teoría de las Areas Culturales surgió en oposición a la teoría de los círculos culturales, sostenida por la escuela llamada Histórico-Cultural. Los círculos culturales fueron elaborados especiolmente para la compresión de las culturas primitivas, o sea aquellas que no participaban de la cultura europea, eje o patrón de las clasificaciones. Con el avance de la ciencia antropológica este sistema no tuvo grandes resultados y la nueva teoría de las Areas Culturales, surgida en los Estados Unidos de Norte América, fué adquiriendo poco a poco mayor validez teórica, su desarrollo "fué gradual, empírico y casi inconsciente" (Kroeber)

El concepto de área cultural comenzó a ser usado como ayuda para la clasificación de las colecciones etnográficas de los museos, basándose sobre todo en líneas geográficas naturales, en lugar de los esçuemas de evolución (Kroeber). El que lo sistematizó y le dió cuer. 
po fué Clark Wissler en su obra "El Indio Americano" en el año 1917, con el fin de orientar sus investigaciones sobre las culturas indias americanas. Como también dice Herskovits, "el desarrollo de este concepto, fué más activo entre los americanistas como resultado de la necesidad de idear una técnica para diferenciar y describir las esferas de la actividad de las costumbres, tenidas por pueblos cuya falta de escritura hacía imposible alcanzar proiundidad histórica en su estudio". Después de Wissler el que dió la base científica al concepto fué Kroeber al estudiar las culturas nativas americanas en 1929.

El Area Cultural es el marco gecoráfico en que se desarrollan culturas similares, formas específicas de vida; concepto que es utilizado para la clasificación de las culturas en determinadas zonas geográficas. Es indudable la importancia que tiene en ella el factor geográfi$\mathrm{co}$, el que le da el substractum, pero éste no es determinante, simplemente se le considera como el habitat, la morada del grupo social que contribuye al desarrollo de determinadas aptitudes por los elementos que le ofrece. Lo importante en este concepto es la cultura, los rasgos culturales que la determinan, y que debe ser considerado en forma preferente. De esta manera "una relativa homogeneidad de cultura y su diferenciación con el exterior" (Herskovits) es lo que determina un área cultural.

No debe olvidarse, ni dejar de lado, que el área cultural es un msdio antes que un fin, porque el fin debe ser la comprensión de los procesos culturales como tales o los eventos históricos de la cultura.

Este concepto de "area cultural permite intentar una serie de esquemas clasificatorios de las culturas, especialmente en Sud América. Por ello es valioso conocer su desarrollo y sentido. Difiere de! concepto de círculo de cultura, el cual significa las diversas maneras como los grupos humanos han manifestado su poder creativo, la consideración de las invenciones culturales y su difusión.

El Area Cultural tiende, pues, a precisar el marco que ocupan determinadas manifestaciones culturales en una zona, basándose primero en su densidad histórica y luego en el estudio analítico de sus rasgos culturales. Hay en su contenido una relación de espacio y tiempo, lo que la hace valiosa y nos sirve para entenderla mejor. La "cotradición" (Linton-Bennett) sería la base fundamental para el criterio de clasificación.

Para la clasificación de Area Cultural se toman en cuenta diversos criterios, principalmente elementos de la cultura material, espiritual, social y aun el ethos de los grupos, para después darles profundidad histó- 
rica y enmarcarlos en el espacio. La correcia distribución de las árear está determinada por los estudios que van haciendo día a día los antropólogos en todo el continente amerisano. Las monogratías, son la Dase de estos esquemas clasificatorios, de allí que especialmente en la América del Sur, ha sido difícil precisar con exactitud las diversas áreas de distribución cultural, por la carencia de estudios detallados en sus diversas zonas. Los recientes trabajos de campo están contribuyendo ¿ hacer más inteligible esta demarcación cultural.

Veamos los intentos de clasificación en áreas culturales de la América del Sur:

\section{1.-Wissler (I917)}

I. Chibcha (Colombia)

II. Antillas

Iîl. Ánazonas

IV. Inca (Andina)

V. Huanaco (Patagonia)
4.--Kroeber (1948)

1. Andina

II. Círculo Cáribe

III. Selva Tropical

IV. Marginal

2.-Krneber (1923)

5.-.-Herskovits (1949)

I. Colcmbia o Chibcha te Murginal

II. Antillas Blolioteca de Letrias Selva Tropical

III. Selva Tropicálorge Puccinelli ConveIIso "Cáribe

IV. Andina o Peruana

IV. Andina

V. Patagonia

3.-Handbook of South Am. Indians (1946)

I. Marginal

II. Selva Tropical

III. Circulo Caribe

IV. Andina
f.-Bennett (1949)

I. Cazadores del Sur

II. Agricultores tropicales

III. Agricultores andinos

IV. Caribe

Como puede observarse a través de estos cuadros desde 1917 a la fecha, la delimitación de las Areas Culutrales para la América del Sur no ha podido precisarse definitivamente. Aun el Area Andina, la que más nos interesá y que cuenta con mayores fuentes de estudio, ha sufrido sustanciales modificaciones. Comparando las clasificacio- 




1.-AREAS CULTURALES SUDAMERICANAS (1923) 


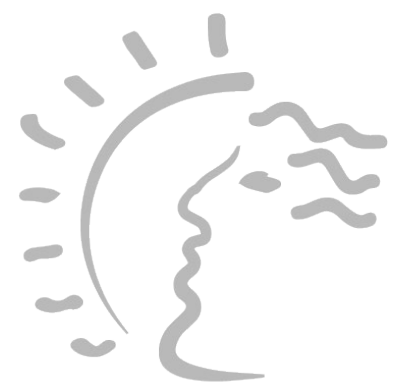

Biblioteca de Letras "Jorge Puccinelli Converso" 


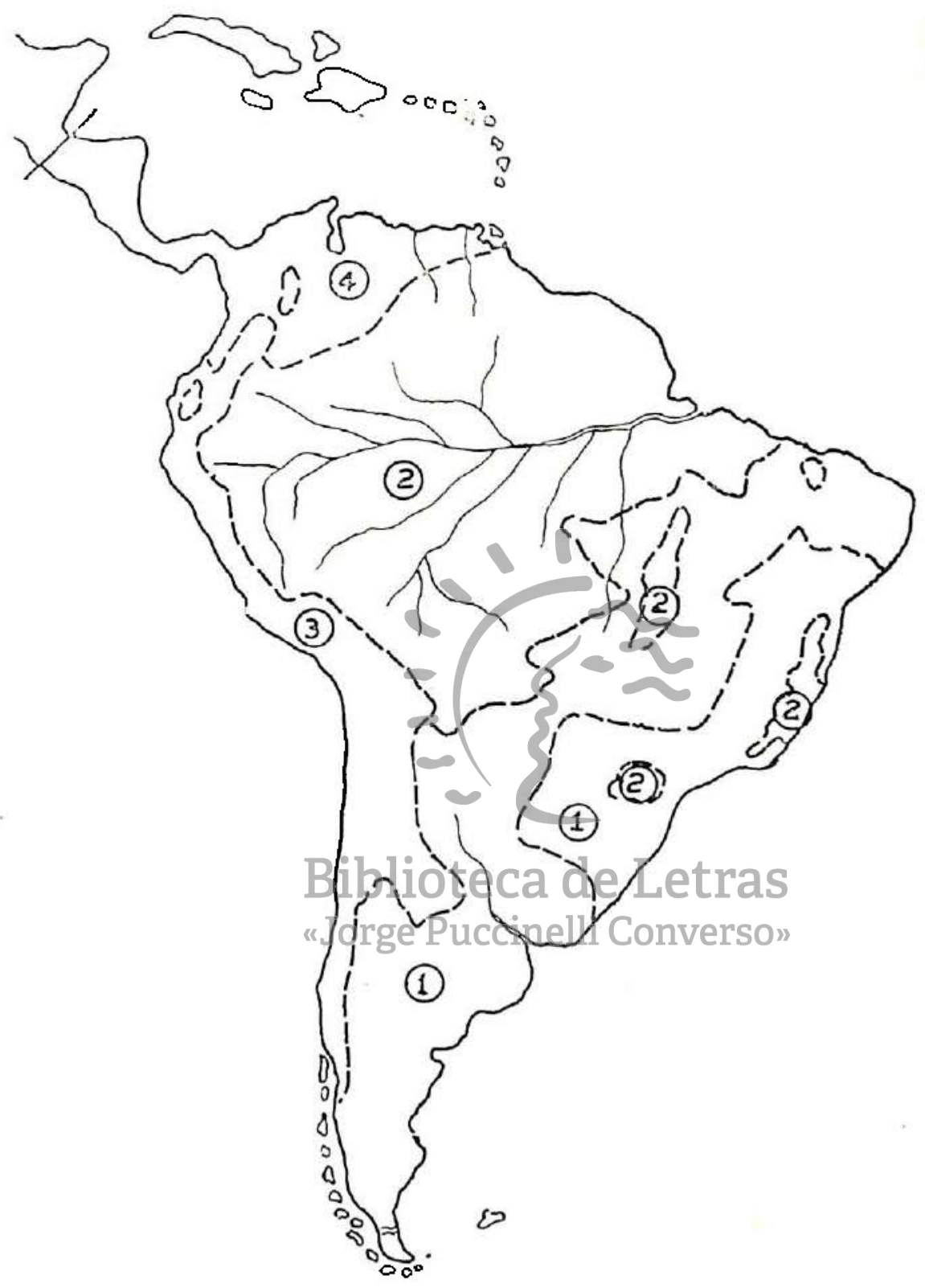

1946. HAND BOOK OF SOUTH AMERICAN INDIANS (Manual del Indio Sud Americano)

2.-AREAS CULTURALES SUDAMERICANAS (1946) 


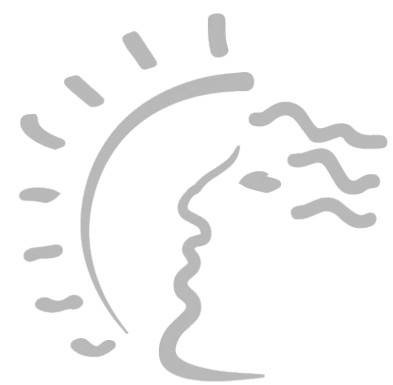

Biblioteca de Letras "Jorge Puccinelli Converso" 




AREAS DE CULTURA NATIVA EN AMERICA DEL SUR (KROEBER-1948) 




Biblioteca de Letras "Jorge Puccinelli Converso" 


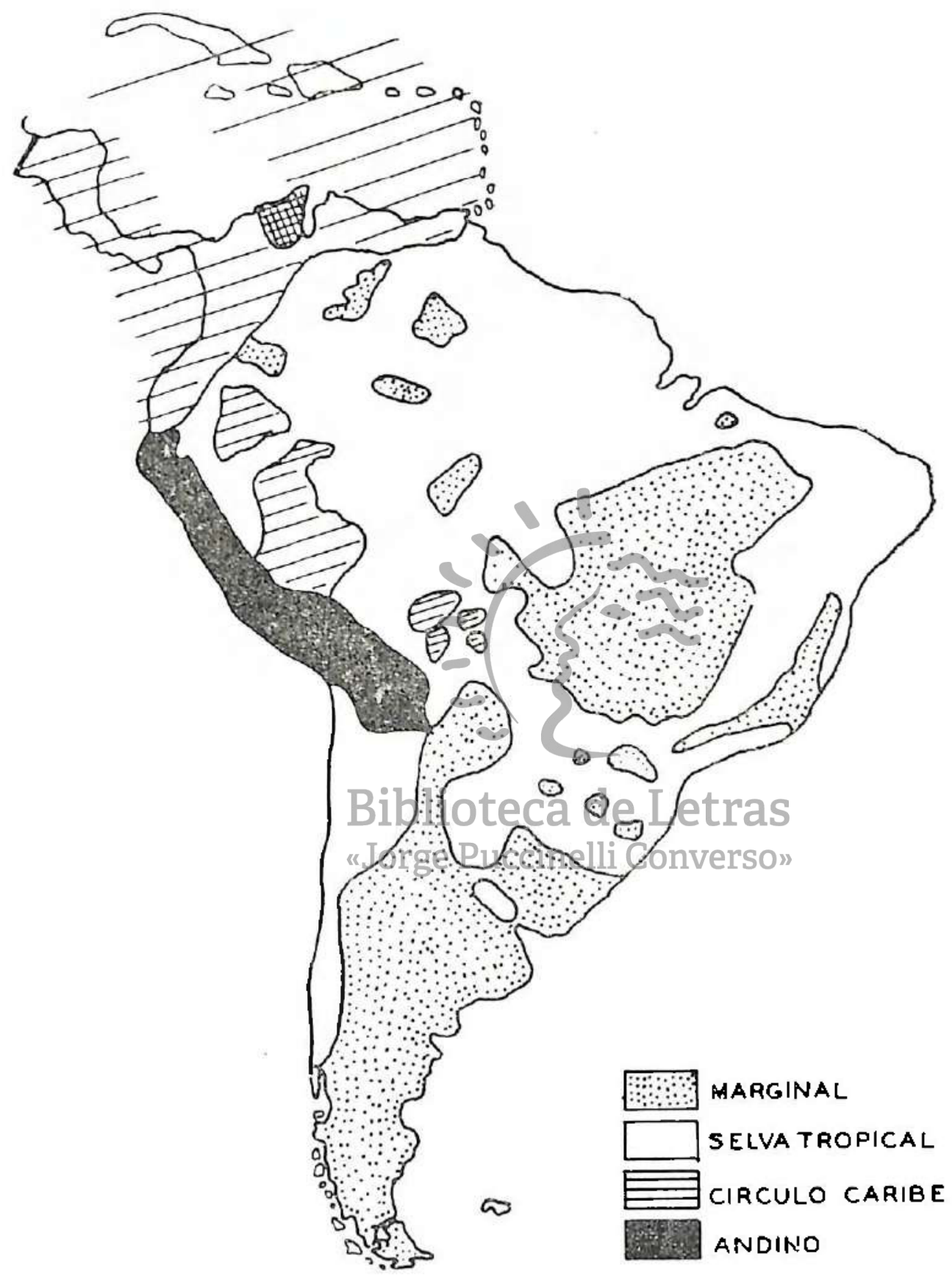

TIPOS DE CULTURA DE SUD-AMERICA HERSXOVITS - 1949

4.-AREAS CULTURALES SUDAMEHICANAS (1949) 




Biblioteca de Letras "Jorge Puccinelli Converso" 
nes de América en general, notamos que las áreas norteamericanas han sido establecidas con mayor exactitud que las sudamericanas. Esto, según Kroeber, es debido a que la búsqueda de datos ha sido intensa y que no ha habido un esfuerzo sistemático para clasificarlas.

El Area Andina, a la que todos los autores consideran como el núcleo de la alta cultura sudamericana, ha sido reducida, ya no se considera el Ecuador, Norte de Colombia como parte de la misma, así como tampoco todo el Norte de Chile; los recientes estudios de Collier y Murray en las Esmeraldas y otros grupos ecuatorianos en 1948 han determinado esta separación; presentan una serie de datos que acercan más esta zona al Area del Círcullo Caribe. Igual sucede con parte del norte chileno que ahora es incluído en el Area Selvática.

Entre estas 4 grandes áreas existe una gradiente cultural, el Area Andina es la que ocupa el nivel más alto, la alta cultura de Colombia donde existió la cultura Chibcha y que ahora corresponde al Círculo Caribe es considerada en el nivel intermedio, y las otras dosi áreas, la Marginal y la Selva tropical dentro de las de nivel más bajo, la baja cultura.

El Area Marginal estaria integrada por los siguientes grupos:

a) Archipiélago chileno: Alacalufs y Yahgans.

b) Tierra del Fuego: Onas

c) Patagonia: Tehuelchelioteca de Letras

d) Pampas: Puelchej yrQuerandíinelli Converso»

e) Uruguay: Charrúa

f) Este del Brasil: pueblos Gë

El Area Selva Tropical comprendería los siguientes:

a) Trópicos del Brasil

b) Este de Bollivia, Perú, Ecuador y Colombia

c) Llanos de Venezuella

d) Sierra de las Guayanas

e) Parte de la sierra del este del Brasil

f) Indias Occidentales

g) Costas de Colombia en el Pacífico y Caribe

El Círculo Caribe:

a) Antillas

b) Cuba

c) Costa de Venezuela: Colombia en el Pacífico y Caribe

d) América Central, desde Honduras' a Panamá 
El Area Andina estaría integrada por:

a) Sierra de Perú y Bolivia

b) Costa del Perú

c) Noroeste de Argentina

d) Norie de Chile

El último diagrama de Herskovits (1949), nos dí una idea clara de la forma cómo están actualmente consideradas las áreas culturales, puede observarse que no hay continuidad en muchas de ellas y la que conserva mejor delimitada su área es la Andina, las otras tres están desparramadas. El Area Selva Tropical es la más extensa y la menos, el Area Andina.

El Area Andina ha quedado delimitada actualmente al espacio geográfico que comienza en la actual frontera ecuatoriana por el norte, por el sur parte del noroeste argentino y Chile, -.. comprendiendo toda la parte andina de Bolivia - por el este la selva y por el oeste el Océano Pacífico. El Perú dentro de esta clasificación, está ubicado dentro de do: áreas culturales: la costa y la sierra dentro del Area Andina y la selva en el Area Selva Tropical. Esto dentro de los líruites actuales del Perú como nación, ya que para la clasificación cultural de la América los límites actuales de las naciones no interesan.

El caso del Area Andinaces excepcional para la más exacta delimitación de su area cultural, pues tiene una gran "co-tradición". Es la zona más rica "en réstos drqueológicostverno "debemos olvidar el papel que ha desempeñado la cultura antigua del Perú en el mundo antiguo sudamericano - la magnífica documentación que significan las crónicas de los siglos XVI y XVII, las publicaciones de viajeros e investigadores españoles, indios, mestizos y extranjeros durante los siglos XVIII, XIX y XX, todo lo cual le da una continuidad histórica valiosa para su estudio clasificatorio.

Conforme van realizándose estudios dentro de nuestra Area And:na, van notándose y apareciendo con bastante claridad diferentes peculiaridades en los grupos que la integran. Esta es una de las tareas qua tenemos los etnólogos peruanos: contribuir a hacer más exacto el conocimiento del área andina, precisar con certeza las diferentes variantes culturales en la gran área. Establecer subdivisiones, niveles culturales; variaciones y características que han adquirido y están adquiriendis los grupos en el Perú actual, en el proceso de mestizaje cultura! en que nos encontramos. 
Estas variaciones culturales las denomino: Sub-áreas culturales, parà no confundirla con la de Area Cultural que correspondería al total, le sub-área sería la sección dentro de una área.

Las sub-áreas presentan la mayoría de ellas "tradiciones culturales locales y entre sí gran aislamiento geográfico", (Bennett) lo que facilita nuestra labor.

También debemos remarcar que esta clasificación de Areas Culturales Sud-Americanas se refiere iz la distribución culiural prehistórica, de indudable influencia en la formación de las nacionalidades, escapa por el momento de la consideración de las nuevas formas culturales que van tomando los diversos países que ahora existen en ella.

Contribuyendo a esta finalidad y después de haber estudiado ir:tensivamente, desde 1948 la Comunidad de Tupe er la provincia de Yauyos, expongo a continuación las características principales de este grupo, bastante aislado en el área andina y que considero una sub-área cultural dentro de ella.

\section{L.A COMUNIDAD DE TUPE}

Tupe, actualmente es el relicto del idioma kauke o jakaro. Este antiguo idioma precolombino difiere del quechua y aymara. Por lo; datos registrados notamos en su composición un mayor porcentaje de palabras aymaras que quechuas, no pudiendo precisar las cifras de este porcentaje mientras nooséconcluya el lifilomellingüístico que está en elaboración. El hecho concreto es que personas que hablan quechua y aymara no pueder. entenderse con los tupinos.

La Comunidad de Tupe está ubicada en la sierra del departamento de Lima, en la provincia de Yauyos. Tupe es la capital del distrito de Lérida y es una de las tres comunidades que integran este distrito. De estas tres comunidades: Tupe, Cachuy y Catahuasi, únicamente en las dos primeras se habla el kauke actualmente, aunque los 183 habitantes de Cachuy pueden considerarse como un débil grupo dialectal del kauke. Las variaciones lingüísticas con la Comunidad de Tupe son evidentes.

Los datos de viajeros y estudiosos nos indican que el área del kauke fué mayor en el siglo pasado y que a fines del siglo XIX se hablaba en las provincias de Huarochirí, Yauyos y Canta

La población de Tupe es de 952 habitantes según el censo de 1940. Por los datos que hemos registrado, desde la visita del Arzobispo Tc- 
ribio de Nogrovejo en 1588 y în02, deducimos que la pobiación no ha sufrido grandes variaciones, casi ha permanecido esiática, bordeando los mil hajitanies. Tcdos ellos son mestizos y bilingües, hombres y mujeres hablan castellano y kauke, siendo este último el idioma familiar y de uso corriente. La cultura de lupe puede considerarse en transición, mestiza con marcada preponderancia indígena.

El pueblo de Tupe a $2,830 \mathrm{~m}$. sobre el nivel del mar, está enmarcado en una quebrada estrecha de $200 \mathrm{~m}$. de ancho como término medio, rodeada por los ríos Chancay y Cuchapaya, que nacen en la puna y que se juntan al pie del pueblo para formar el río Tupe.

En la Comunidad hay cinco centros poblados: Aiza con 286 personas; Colca con 121 personas; Vishca con 53 habitantes (1948), Wanturo con 21 habitantes y Tupe con 524 habitantes. En la puna viven esporádicamente algunas familias, en 1950, registramos 80 personas. Además hay grupos de casas en Anchike, Chiure y Cuya, la primera en la quebrada norte con 15 personas, la segunda encima de Aiza con 12 habitantes y la tercera al lado de Coilca, cuyos habitantes son considerados como colquinos.

En Tupe hay Gobernación, Alcaldía, Juzgado de Paz, Patronato Escolar, Administración de Águas y Junta Comunera. Está registrada en el Ministerio del Trabajo y Asuntos Indígenas como una Comunidad Indígena.

Su complejo enno-botánico está basado en los siguientes productos:

Especies aufóctonás Puccinelli Conver Especies alienígenas

papa (solanum tuberosum)

maíz (zea mays)

frejol (phaseolus vulgaris)

olluco (ullucus tuberosum)

achira (canna adulis)

yacón (polymnia sonchifolia)

ají (capsicum)

granadilla (pasiflora ligularis)

mito (carica cadicans)

zapallo (cucurbita)

calabaza (cucurbita moschata)

sauce (salix humboltiana)

nogal (juglans neotropical)

aliso (alnus jorullensis)

maguy (agave americano) trigo (tritivum sativum)

cebada (hordeum sativum)

haba (vicia faba)

arveja (pisum sativum)

alfalfa (rnedicago sativa)

eucalipto (eucaliptus globulus) 
En cuanto a la fauna doméstica el cuadro sería el siguiente:

\section{Autóctonos}

auquénidos: llama, alpaca, vịcuĩa perro cuy

\section{Alienígersas}

El pueblo está dividido en dos barrios y seis parcialidades o "ayllus". Los barrios son: Cucharga el de arriba y Malambo el de abajo. Los ayllus: Nutko, Kallana, Jilasullka, Yañak, Aiza y Pursuilka. Actualmente funcionan como Institutciones las parcialidades de Pursullka y Yañak con sus Juntas Directivas, sociedades perfectamente organizadas con estatutos, encargados de celebrar la fiesta de Corpus Christi. El resto de las parcialidades ha perdido su antigua función y sólo queda el recuerdo de ellas.

- Los tupinos son personas sumamente vivaces, de mente ágil, especialmente las mujeres. La hospitalidad casi-es desconccida en su acepción verdadera debido aJ süpodàlexperiencialconleloexterior. Es sorprendente el papel que desempeña la mujer en el grupo dondequiera que se le encuentre, en cualquier actividad que realice, su personalidad se impone, tiene gran dominio, mando; y se respetada por tcdos. El hecho de que participe en las diferentes sociedades religiosas, cofradía, donde como socia de ellas debe cumplir con las obligaciones que exige la institución, la ha convertido en experta conocedora de las obligaciones que debe tener en el grupo; además, como cada año debe pagar cierta suma de dinero como interés por el capital que adeuda a la sociedad religiosa, entiende de tantos por cientos, y las fundamentales operaciones aritméticas. Una tupina en cualquier oportunidad puede decir exactamente el seis, dc$\mathrm{ce}$, veinte por ciento de una suma que no exceda de cien soles. En el trabajo tiene gran responsabilidad, sobre todo en las labores agrícolas que la obliga a permanezer contínuamente en la comunidad; el hombre, en cambio, tiene un mayor contacto con el exterior, conoce 
Yauyos, la capital de la provincia, Lima y Cañete y antiguamente, con motivo del comercio de ganado, recorría zonas distintas, tales como los departamentos de Ayacucho y Huencavelica. Es a través de ellos que se ha producido una mayor aculturación en el grupo. Esto actualmente está perfectamente reflejacio en todas lus actividades de la Comunidad, sin que signifique pérdida de prestigio en la mujer.

Llama la atención la resistencia física de la mujer: es quien carga la cosecha, tanto de papas como de maíz, desde lugares apartados hasía el pueblo, en grandes sacos de casi un quintal que lleva en la espalda sujetos por una faja que sostiene on la frente. Las labores penosas de la siembra, cuspa, recissra iaporques) y cosecha están íntegramente a su cargo. Los hombres únicamente roturan la tierra y ayudan en el carguío de las acémilas. Es en el riego donde la ayuda del hombre es mayor.

La propiedad es particular, cada familia es dueña de la casa dorde vive, de corrales y de extensiones de tierras de cultivo, en diversas partes de la quebrada. La puna, con sus pastos naturales y ciertas zonas en la parie alta, dedicadas al cultivo de papa, son de propiedad comunal; los pastales se sacan a remate entre los tupinos cada primero de enero en acuerdo comunal y las zonas de cultivo pueden ser ạrovechadas libremente según el empeño y decisión que tenga cada familia, determinada en parte por la capacidad y número de miembros.

Todas las tierras de cultivo estón situadas en andenerías y el principal instrumento de Gabranza es la laklia lio accidentado del terreno y la estrechez de los andenes no permiten el uso de otras ayudas para la roturación de la tierra. La taklla, que está así condicionada por el medio, ha sido modificada con la adaptación de la punta de acero y en su utilización el grupo la usa como en tiempos pasados. Las prithcipales siembras, en que todavía se conserva el ritual de fiesta, son hechas colectivamente, unos a otros se ayudan. La siembra del maiz en Aiza y de la papa en Pupre constituyen espectáculos que llenan de admiración a las personas que los presencian. Los tupinos forman gripos de seis a doce personas, uno al lado de otro y con gran sincronización aran los andenes en medio de disparos de ccheles y gritos de alegría, mientras el dueño de la tierra convida chicha y alcohol; los compadres y comadres engalanan a los dueños y las mujeres de edad al finalizar la siembra jarawan, entonan una canción de súplica a la tierra a fin de que rinda buenos productos. La cosecha ha perdido completamente su sentido colectivo, ahora la realiza independientemente cada fa- 
nilia. El instrumento femenino de labranza es la nampa, un escardillo que les sirve para sembrar, cuspar y cosechar. La taklla y la nampa son instrumentos antiguos.

I. a ganadería ha sufrido ur cambio con la introducción de las especies importadas, que han venido a sustituír a las autóctonas. Los auquénidos constituyeron hasta la introducción de las nuevas especies la única fuente de recursos, como lo fueron en todz el área andina, ellos proveyeron de lana para la confección de sus vestidos, carne para la alimentacién y de elementos de transporte, fuera de otros usos secundarios. La nueva fauina desplazó a la antigua hacia su verdadero medio, la puna, donde actualmente existen en gran cantidad, y produjo cambios en el vestido, alimentación y transporte; adaptaciones en la técnica y arte y transplantes culturales en la magia. Cambios que no han operado substituciones sino más bien adaptaciones y asimilacićn. Así la lana de los auquénidos actualmente es la base principal par.a la confección del vestido de la mujer. El cambio en el vestido de los hombres que es ahora occidental se debe principalmente a su mayor movilidad fuera del grupo. Comc en pocas regiones del Perú el vestido de? las tupinas conserva muchas piezas autóctonas, el anaco, de finísima lana de alpaca negra, las mantas de igual material, fajas de alpaca $y^{\circ}$ toda una variedad de pequeñas mantas para el fiambre y para adorno, lejidas en lana de alpaca y vicuna. La lana de los ovejunos ha sido aceptada ampliamente y la utilizan para los tejidos de calidad inferior, para la confección de nuevas piezas de vestido, como en el caso del poncho, y en algúnasl"Grdimbresnalohdeolaverama"es siempre de lana de alpaca. En ell transporte, la llama ha sido completamente reemplat zada por el ganado caballar, mular y asnal.

En el aspecto mágico, todo el complejo vinculado a las especies autóctonas ha sido adaptado a la nueva fauna, es allí donde la persistencia de sus antiguas costumbres y creencias subsiste con todo su vigor, trasplantado a lo nuevo. La fiesta de la Herranza (marca del ganado). nos permite apreciar con toda nitidez esta adaptación cultural.

El kauke, el vestido de las mujeres, el papel que las mismas desempeñan en el grupo, la supervivencia de elementos culturales aborígenes, el vakataki, (baile y música típicos), la fiesta de la siembra, las sociedades religiosas y la herranza, son las principales manifestaciones culturales que caracterizan a la comunidad de Tupe.

El trabajo tiene tres formas peculiares: la minga que denominan al servicio que puede prestar un hombre o mujer sujeto al pago de un iornal; la turna ayuda voluntaria con su respectiva retribución: la re- 
turna; y là fujiza trabajo comunal, colectivo. La minga tiene en esta comunidad una acepción que diffiere del patrón general del área andine: la segunda representa al ayni $y$ a una variante del misrno; la tercera sería la verdadera minga.

Un cuadro de la distribución del trábajo sería el siguiente:

Distribución del Trabajo

Hombres

Agricultura

Arado

Piego

Transporte de la cosecha
Mujeres

Desterronar

Despajar

Sembrar

Cuspar y recuspar (aporques)

Riego

Cosecha

Transporte de la Cosecha

Desgrane
Ganadería

Pestoreo

Recolección

Leña y Agua

\section{Tejidos}

En telar: ponchos

anacos

mantas

marate (tipo de faja) preparación de la lana

Kánas (cintas para el cabello)

Warakas (tipo acordonado)

Fajas (en telar)

Labores domésticas

Lavado de ropa

Lavado de ropa

Zurcido

Cocina

Molienda

Crianza de Niños 
Constiucción de casas

Toda la construcción

Sogas de amarre

Cordelería

Sogas de maguey

Sogas'de maguey

La alimentación de la Comunidad se basa en el complejo de plantas que cultivan, especialmente en la papa y el maíz, las que acompañan con queso. En la elaboración de la dieta diaria se aprecia cierta pobreza, tanto en su preparación como en la cantidad. Unicamente las fiestas dan ocasión para variar el menú y comer abundantemente. Los alimentos simplemente cocidos y sin aderezos constituyen su técnica culinaria. La bebida típica es el chamiscol una infusión de té o huamanripa con alcohol, limón y azúcar. Unicamente utilizan la coca cuando realizan trabajos en la puna.

La vivienda típica está compuesta por una sola habitación de pìdra con techo de paja (ichu) donde duermen y depositan sus cosechas. Al lado hay un pequeño espacio pircado que sirve de cocina, mas erı la época de lluvias se cocina en el interior de la casa. No existen patios y las casas están distribuídas dentro de un plano de ciudad más o menos regular. Otras viviendas de construcción reciente tienen techos de calamirła, teja o eternit y sus paredes son de piedra o adobes, sus pocos enseres consislen de algunas mesas y catres de madera y en aigunas familias de una máquina de coser. Los utensilios de cocina son: vasijas de barro, platos dé loza, collase dè Cluminió, daides de zinc, cubiertos de metal y madera y una profusión de jarros de hojalata. La mayoría elementos nuevos perfectamente aceptados.

Para la compra de productos complementarios de su dieta, artículos manufaciurados, como vestidos para los hombres, utensilios de cocina, herramientas, etc., consiguen dinero vendiendo sus animales, pues ésta es la principal finalidad de la cría de porcinos, ovejunos, vacuros y caprinos. Algunas familias realizan trueque con los sobrantes de sus cosechas, papa, maíz y frijoles, con los comerciantes que acliden al pueblo. El queso que preparan les sirve para cambiarlo por frutas, yucas y camotes en el valle de Cañete. Los hombres tienen a su cargo este negocio. La posesión del dinero en una familia no tiene un fondo común, tanto el hombre como la mujer lo administran independientemente, cada uno sabe la parte que le es propia y siempre tratan de no mezclarla. Hay algunas personas que tienen tiendas que proveen lo necesario al pueblo. desde medicinas, cuadernos, lico- 
res, hastá prodictos alimenticios, estas personas son de las más accmodadas. No todos pueden dedicarse al comercio, porque además de secesitar un capita! inicial y mucha paciencia, deben tener cieria holgura que les permita disponer de tiempo para lcs viajes.

In actividad económica que caacteriza el grupo está basada en la agricultura, la qanadería y e! comercio. Para matizar lo penoso que es dedicarse íntegraments a la lucha por la existencia, el grupo tiene momentos de expansión deniro de cada una de estas actividades, fiestas como en la siembra, herranzas en la ganadería y numerosas celebraciones religiosas. Existe un cornpieic de fiestas relicyiosas íntimamenie vinculadas: la Fascua de Navidad, '25 de diciembro), la Pascua de Reyes ( 6 de enerc) y la Candeleria 12 de tebrero). Los grupos de baile, llamados pandillas, con sus mayordomos y mayorales, organizados por las Sociedades Religiosas, funcionan de acuerdo y en igual forma en las tres celebraciones. Este conjurio de fiestas se caracteriza por el baile llamado La Pascua, en el que dos hombres, llamados pastores, con un sistro (sonaja) en la mano derecha dirigen respecitivamente un grupo de 5 á 6 mujeres visiosamente ataviadas, auienes constituyen la manada, acompañados por una orquesta compuesta por una arpa y dos violines, tocando el tono llamado también Pascua. La alegría llega a su culminación el 2 de febrero, cuando dos o tres pandillas entran en corupetencia en la plaza principal del pueblo durante dos días.

Otro complejo de celebraciones es el de la Semana Santa que, a diferencia del anterior, en que $4 a$-iglesia permanece al margen, en éste todo gira en tornoodee ellacchiayelrezos nyteprocesiones desde cuatro semanas antes.

La fiesta principal, y en la que participa toda la Comunidad intensamente, es la Herranza, la marca del ganado, que cada dos a tres años llevan a cabo las familias tupinas durante los meses de junio y julio. En la Puna de Tupe, la herranza de los auquénidos se realiza en el mes de agosto. Los actos mágicos como el ritual de la sangre, los que realizan con los pedazos de oreja cortados de los animales, la preparación de la uksa (maíz blanco molino), la finalidad de pedir protección a los espíritus de los cerros para que cuiden el ganado, el vakataki como música y canto - que tiene su origen en esta fiesta -; constituyen la médula de sus prácticas mágicas, haciendo sumamente interesante la fiesta de la Siñayla o marca del ganado (Herranza). Fácilmente pue. den constatarse supervivencias mágicas y, toda una nueva adaptación en que la marca de hierro pierde su importancia ante la señal de los animales: el corte de orejas, esencia de la antigua práctica ganedora. 
Acompaña a la Herranza un conjunto de tradiciones y variantes que dan sentido a la comprensión total del ritual. Tras el biombo de lo importado supervive plenamente la antigua tradición.

El patrón del pueblo es San Bartolomé, de ahí el nombre exacto de la comunidad, San Bartolomé de Tupe, como vemos en los documentos de los siglos XVI y XVII y en los relatos de viajeros posteriores; su celebración es el 24 de agosto y dura una semana la fiesta en su homenaje. Es la única vez que el Párroco de la doctrina de Yauyos acude al pueblo lo que aprovechan para la celebración de matrimonios, bautizos y misas de difuntos.

A través del ciclo vital podemos adentrarnos mejor en el conocimiento de los patrones dominantes del grupo. Los nueve meses que preceden al nacimiento de un niño no alteran mayormente la vida normal de la madre, su ritmo de trabajo continúa sin variantes hasta el momento del parto. La necesidad de trabajar para subsistir contribuye a este acondicionamiento. Los hijos son deseados por los tupinos porque ellcs saben que con una familia numerosa pueden vivir mejor, sultivar más tierras, distribuir mejor las diferentes faenas diarias. Es el hombre quien atiende a la mujer durante el alumbramiento. El parto ocasiona transtorno en la familia, porque el cuidado de la tierra y sobre todo de los animales que diariamente deben ser llevados a pastâr quedan casi abandonados. Apenas la mujer se siente con fuerzas reanuda su labor llevando a suphijo cargádo a la espalda en una cu. aa (tira), elemento que superyive en muchas regiones del Perú, en la inisma forma que la "presenta Filipe Guamán Pomä de Ayala, en si "Nueva Coronica y Buen Gobierno".

La primera ceremonia a que se ve sujeto el niño tiene carácter religioso, el Agua de Socorro, que se realiza a los pocos días de nacido y mientras se espera la llegada del cura al pueblo, es un bautizo hecho por laicos y que une por parentesco espiritual a los compadres en la misma forma que el verdadero bautizo católico.

La crianza del'niño está a cargo de la madre y en ella no hay disciplina, la criatura con su llanto determina la atención de la misma y ésta solícita acude a su llamado.

A los tres años celebran la ceremınia del quitapelo o sea el primer.corte de cabello, de gran trascendencia en la vida futura, aunque únicamente reservada para los varoncitos. Este hecho les reporta un beneficio económico, de esta manera el rutuchicuy antiguo adquiere en Tupe una función puramente económica. El día del corte de cabello la familia reune a sus parientes y amigos, se nombra padrinos y 
en medio de gran fiesta recolectan dinero de iosios los asistentes para formar un fondo que sirva al niño durante lia edad escolar, muchos de ellos logran juntar hasta mil soles. El dinero reunido el día de la fiesta es entregado en préstam:o a uno de los asistentes, con un interés determinado; $y$, anualmente se realiza la cuenta, devolución del dinero con sus respectivos intereses, se hace nueva colecta y nuevi entrega del dinero a un tanto por ciento de interés. Esto se repita unos seis u ocho años.

En esta primera etapa de la vida la mortalidad es elevada, de ahí que la vida de los niños no se considere segura, mostrando calma e indiferencia los padres ante la muerte de un infante.

Entre los seis y diez años ya el niño es incorporado a! trabajo, des. de esta edad adquiere responsabilidades que acepta gustoso, en parte porque está condicionado desde la infancia al ver trabajar diariamerte a sus padres y sus mismos juegos están vinculados a las actividades económicas. Los niños juegan construyendo casas, arando la tiera con pequeñas takllas de juguete, las niñas con nampas simulando cosechar, preparando comidas, etc. La iniciación en el trabajo comienza con el pastoreo y luego con pequeñas ayudas en la agricultura. Este hecho que los condiciona para mayores responsabilidades, les causa un trastorno en sus labores escolares, interrumpiendo la enseñanza que puedan recibir en la escuela. Así el tupino es educado más baju, sus patrones tradicionales quéchablo epatronesa educativos instituídos. L. deficiencia de la educación oficializada se percibe claramente en todas las comunidades peruanas, porque no han logrado captar la cultura del grupo al cual tienden a educar.

En la adolescencia y juventud el tupino no sufre las conmociones que pueden observarse en otros grupos, de antemano conocen el samino a seguir, las posibilidades en su vida futura son simples, casi únicas: seguir la tradición, les pocos que escapan de ella son raros. No hay frustración, ni desilusión cuando están formados, porque la vida adulta los encuentra perfectamente capacitados para cumplir con sus obligaciones dentro de la comunidad en forma eficiente.

La gran movilidad de las muchachas dentro del grupo; debido a sus actividades pastoriles y agrícolas, en las que realizan tareas individuales, hace que tempranamente lleguen a tener experiencias sexuales, aunque sin llegar a la promiscuidad. Lo que puede observarse es una marcada tendencia de los padres a atrasar el matrimonio de sus hijos e hijas, por el temor de verse privados de la colaboración que les es vital en su economía y también por el peligro de ver desmem- 
breda la propiedad. La propiedad en la comunidad está tan fragmenlada por la herencia que so ha llegado al extremo que un andén de unos $12 \mathrm{~m}^{2}$ pertenezca a tres y cuatro personas. Es mayor el número de mujeres que permanecen solteras, siendo frecuentes los matrimcnios e:i que la mujer es de mayor edad que el hombre. Una mayo. ria de tupinos abandona continuamente el grupo para buscar acomodo en ciudades de la costa, Lima principalmente. La colonia de tupinos en Lima está integrada por casi 70 hombres jóvenes, en su mayoría del cuerpo de la Guardia Civil. Este desplazamiento resta posibilidades de matrimonio a muchas mujeres. El patrón de la comunidad en cuan. to a las relacioneș sexuales está completamente en transición, nada defjnido puede encontrarse como norma. El único tabú es el de padres, hijos y hermanos. Aunque todo el pueblo murmure de un hombr? que conviva con la madre y su hijastra al mismo tiempo o de una mujer, con el hijastro o con el cuñado, es frecuente observar que muchas personas lo hacer: sin interesarles mayormente el comentario público. El matrimonio civil ha adquirido mayor jerarquía que el religioso, aunque la necesidad de presentar un cerfificado médico produce dificultades que ocesionan trastornos en las uniones y las motivan al margen de lo legal.

La residencia de las uniones es neo-local. La familia es típicamente nuclear, reconociéndose las dos ramás de parentesco. La descender. cia es patrilineal, måsola mujefcasáda ñolleva el apellido del marido sino que conserva el propio. La interesante es el papel preponderante de la mujer que marca el ritmo de la comunidad y su gran conservadorismo. La vida familiar dentro del hogar apenas tiene significa. do, lo recargado de las tareas determinan este hecho.

La ancianidad es considerada en forma completamente indiferente. L.os viejos no tienen ningún papel que los sindique como consejeros del grupo. Si han ocupado un posición holgada o tienen hijos la pasan con relativa comodidad, lo contrario, que es lo corriente sobre todo en las mujeres determina una vejez triste y desamparada. En este caso la actitud de los tupinos es simplemente de lástima.

Las erifermedades causan sus mayores trastornos en la primera etapa de la vida. Los curanderos no gozan de ningún prestigio. Los romedios caseros son la base de las curaciones, especialmente se basan on infusiones. El grupo ha aceptado nuevas medicinas tales como analgésicos, ungüientos, frotaciones, inyecciones aplicadas por aficionados. etc. Lo "frío" y lo "caliente" tienen gran importancia en el diagnóstico $y$ en el remedio dentro del recinto familiar. 
La etapa final del ciclo vital no tiene mayor trascendencia que un simple lamento por la pérdida del ser querido y enfrentarse a los pro. blemas de la herencia y de reemplazo en las labores. No hay hacia la muerte una actitud fatalista. Es considerada como normal entre los anciancs y la aceptan resignadamente en los niños. El entierro de los niños es acompañado de música, baile y comida, mientras que en $€$ ! de los adultos celebran la noche del velorio el "juego de los cinco" o sea la rememoración póstuma de los sucesos que constituyen la norma dミ vida del tupino; con lo que demuestran sus patrones y actitudes ante ambas muertes. No existe una actitud de rebeldía frente a la muerte.

La religión no presenta ningún conflicto como en las comunidades vecinas con la introducción del adventismo, ellos han aceptado las enseñanzas de los misicneros y curas católicos que los han visitado. Lia Iglesia continuamerte les hace recordar estas ideas y las fiestas del calendario católico los condicionan día a día al concepto de lo sobrenatural en forma diferente a su antigua tradición. Aparte de estas consideraciones específicas sobre la actitud del grupo ante el problema de la divinidad, existe una institución, Cofradía, que adquiere en TLpo una modalidad peculiar, con las características de la forma implantada en su introducción en los siglos XVI y XVII. Existen en el pue. blo unas treinta sociedades religiosas, cofradías, bajo la advocación de un Santo o Santa, cada una cuenta con su propia junta directiva y con local propio llamado caltón donde la víspera de la celebración se reunen sus sccios y en medio de una alegre y festiva ceremonia, acompañada por música de vacáaki, realizan su cuentas. Hombres y mujeres pertenecen a estas sociedades por herencia de padres a hijos y tambión por matrimonio. Hay unas cuantas sociedades exclusivamente de mujeres. Cada sociedad funciona como un banco, al que los socios le son deudores en dos formas: con deuda activa y con deuda pasiva. La primera consiste en el préstamo que cada persona solicita de la sociedad el día de la celebración para realizar un negocio o adquirir un implemento. Dinero que puede pagar el año siguiente o a largo plazo, estando obligado a abonar un tipo de interés que los miembros de la iunta directiva señalan. Cuando muere, la deuda pasa a los herederos nor partes iguales, esto los hace ingresar como socios y así se forma la deuda pasiva, o sea aquella que se tiene por herencia.

Mas, el verdadero origen del capital pasivo de cada sociedad es que en una época remota, un número de personas se agruparon y deridieron formar una sociedad religiosa y para ello dieron una sumz de dinero, cien soles generalmente, que sirvieron para la construccićn 
del local y la compra de libros para los estatutos y cuentas, vestidos para el sacerdote, el santo y el mobiliario. Ese dinero inicial fué una donación, como resultado de la mayor devoción religiosa del grupo en el siglo pasado, ahora esto ha decrecido y solamente unas quince sociedades mantienen cierta pujanza. Desde un siglo atrás viene por herencia a tcdo tupino su inclusión en una o más sociedades y la deu. da de una suma determinada que sus antepasados solicitaron a la misma. Esto constituye el capital pasivo.

El día de la cuenta ofrece gran interés porque permite conocer mejor al tupino en su relación con el grupo. Hábiles en el cálculo, expertos en el acomodo de cifras para las deudas, dan al dinero un valor fuera de lo común, un centavo o dos, son motivo de fuerte querella. Ese mismo día, año tras año, realizan una kermesse, o sea un remate en subasta pública; uno de los más ocurrentes del grupo vende al mejor postor frutas, panes, dulces, cigarrillos, etc., que previamente han obsequiado los socios, mayordomos, mayoralas; y el dinero que la sociedad obtiene de la venta sirve para pagar al cura cuando viene al pueblo a celebrar una misa al santo de la sociedad y además para ir aumentando el capital de la institución. Todo el complejo roígioso está asociado a la cofradía que tiene en Tupe características bastante diferentes a otros lugares del Perú.

La magia no tiene el vigor que en otras comunidades del Perú, el hombre no sufre de gran inseguridad dentro desu medio, no hay fuertes heladas ni sequías que echen a perder las sementeras, ni es zona malsana para la vida, de manera que más bien se" presenta en las prácticas ganaderas, pues los animales, debido a la configuración del terreno, sufren desbarrancamientos, o sea que es la propiedad la que afronta mayor peligro, asociando por lo tanto a ella sus escasas actividades mágicas: relación con los cerros, ofrendas a los mismos, conopas y el complejo mágico que acompaña a la herranza. Es interesante anotar la creencia en kékkes y karkarias, los primeros serían los espíritus de las persorias adúlteras, hombres o mujeres, y la segunda el espíritu de lcs compadres que violan el tabú sexual que pesa sobre ellos. Este gran temor de los tupinos que se manifiesta especialmente en las nc. ches de luna, presenta contradicción con la carencia de un patrón rígido en tales relaciones. Las creencias asociadas a los fenómenos atmosfériccs completan su cuadro mágico.

La escuela a pesar de contar tantos años de su creación no ha logrado introducir mayores alteraciones en la vida del grupo, ni ha pro- 
ducido cambios substanciales. Ningún maestro ha sabido comprende: e! grupo.

El gotierno de la comunidad y zu control depende de las autoridudes localez oue son nombradas sigulendo e! patrón de la organización politica poruana. Unicamente el l': de enero de cada año el grupo en reinicon general lel artiguo CAMAOUICO) corserva la antigua tradisión de la comiunidad. Alli se coman deterninados acuerdos para la narcha de: pueble, arriendo de los pastos punales, decisiones para realizar determinados trabajos en bien del pueblo tales corno construrcićn de la escuela, de la casa cural, reparación del cementerio, de la cárcel, arreglos en los caniros, reclamo por los linderos de la comunidad, etc. Trabajos todos que se lloven a cabo durante el año colectivimente. La escuela fué construida en los años 1948 y 1949 en trabaio comunal, dirigides por el Personero y con el control de les autoridades políticas y judiciales, estando distribuícios los jefes de familias en 18 chadrillas, cãda una con quince o veinte integrantes y su jefe. Así el zobierno y el control del grupo se rigon por patrones nuevos, solamente actúan en equipo para obras del bien común.

Como hemos manifestado anteriornente el idioma contribuye fundamentalmente a diferenciar este grupo de otros, es indudable gide debe haber existido en la zona clertas condiciones para que úricamente ella continúe como un relicto. Tal vez Tupe haya sido el núcleo del idioma desde tiempos preífitos?. Su relación Son el quechua y el aymará es un problemagendientel deiresolverrson los lingüistas quienes tiene la palabra.

Los restos arqueológicos en Tupinachaca, donde se encuentran ruinas de construcciones, cementerio y pictografías', de Chuchu, de Cambandure y de Ciudad pueden dar mucha luz sobre la antigüedad de la zona; hemos encontrado fragmentos de cerámica del estilo Chincha, irozos de tejidos del estilo llamado por Kroeber "interlocking", vasijas de cobre, pictografías de estilo Chincha, restos de poblaciones con las clásicas técnicas denominadas por Tello "ohaucallas", mucha influencia de Tiahuanaco sobre estilos locales y nada Inca.

La historia nos ayuda al precisar la gran antigüedad y aislamiento de Tupe. Los Wankas y Yauyos tuvieron marcada influencia en Tupe. El valle de Cañete y Yauyos fueron conquistados por Tupac Inca Yupanqui casi en las postrimerías del Imperio Inca. El primer arzobispo de Lima, Toribio de Mogtovejo visitó Tupe en 1588 y en 1602; los extirpadores de idolatrías lo visitaron intensamente desde 1590 hasta fines del siglo XVII; documentos de hechicerías de 1660 nos ofrecen da- 
tos de nombres de lugares de Tupe y de creencias que concuerdan actuälmente. Los dominicos fueron los que primero se establecieron en Yauyos y seguramente quienes fundaron la Iglesia de Tupe; otros arzobispos y obispos lo visitaron posteriormente; Cosme Bueno y Antonio Raimondi nos dan también noticias del pueblo, de sus famosos 5.000 escalones; Larrabure y Unánue, Barranca y Villar, en el siglo pasado, traen datos lingüísticos del kauke, y Tello en 1925 y Farfán en 1946 son los únicos que en este siglo se han ocupado del tema. Pocas noticias e informaciones en total. Lo escabroso de la zona ha determizado el aislamiento e ignorancia de la historia de Tupe y con ella de! jdioma kauke.

Estos datos que escuetamente caracterizan a la Comunidad de Tupe tratan de adelantar que el área del idioma kauke en el Perú constituye una su'b-área cultural dentro del Area Andina.

Una amplia monografía está en preparación por el que esto suscribe en colaboración con un equipo de etnólogos.

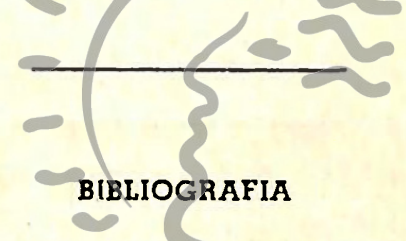

Bennott, Wendel! C. y Bird, Junius

Andean culture history

Ärrerican Museum of Natural History. Fandbook Series Nê. New York, 1949.

(Traduccirin: Miseo de dar Cultura Peruana). lli Converso»

Bennetl, Wendell C.

"The peruvian co-tradicion"

En:

American Antiquity. Vol. XIII, number 4, p.2-7 abril, 1948.

(A reappraisal of Peruvian Archāeology. Memoirs of the Socioty for American Archaeology).

Cooper, John M.

"Culture diffusion and culture areas in southern south American"

En:

Actas del Congrés Internacional do Americanistas. Compleronder de la XXI sesion.

Douxiéme partre, tenue a Göteborg en 1924, Göteborg, 1925, p. 406-421.

Encyclopaedia of the Social Sciences

Vol. 3-4 (Bri-Dan)

Mac Millan 1942. New York. Vol. 4 Culture Area, pp. 646-647.

Herskovits, Melville J.

Man and his works

New York, 1949, Alfred A. Knopf. Part. IV, cp. XI, XII p. 167-200.

Kroeber, Alfred L. 
Anlropología General

Fondo de Cultura Eccnómica. Kéxico, 1345. cops, ZII. XIII, rp. 303-397.

Krceber, Alíred L.

Cultural and nalural areas of nativo north America, Univorsity of California Press.

Berkeley. Los Angeles. 1947.

Kroeke:. Altsed L.

Anthropology

Harcourt, Brace and Company. New York, 1948. cap. xviii pp. 772-839.

Valcárcel, Luis $\mathbf{E}$.

Copias mimeográticas del curso de Intrcducción a la Elnologia. 1950. Universidad de San Marcos، Iima.

Wissler, Clark

The American Indian

Oxford University Press, Now York, 1938 (3ra. ecición), cap. 1.

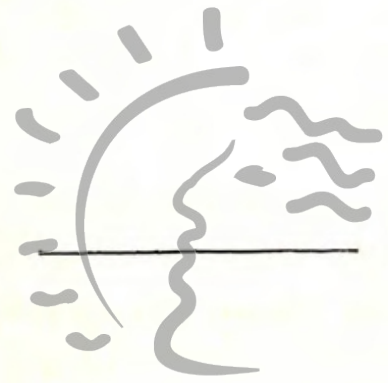

Biblioteca de Letras

"Jorge Puccinelli Converso" 